\title{
Determining sex with the clavicle in a contemporary Spanish reference collection: A STUDY ON 3D IMAGES.
}

Ruiz Mediavilla, Elena, Perea Pérez, Bernardo, Labajo González, Elena, Sánchez Sánchez, José Antonio, Dorado Fernández, Enrique y Santiago Sáez, Andrés.

Cita:

Ruiz Mediavilla, Elena, Perea Pérez, Bernardo, Labajo González, Elena, Sánchez Sánchez, José Antonio, Dorado Fernández, Enrique y Santiago Sáez, Andrés (2016). Determining sex with the clavicle in a contemporary Spanish reference collection: A STUDY ON 3D IMAGES. Forensic Sci Int, 261 (163), 1-10.

Dirección estable: https://www.aacademica.org/elenalabajogonzalez/27 ARK: https://n2t.net/ark:/13683/pcQr/AT5

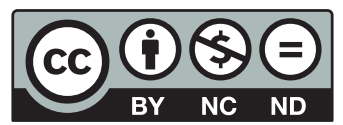


Forensic Anthropology Population Data

\title{
Determining sex with the clavicle in a contemporary Spanish reference collection: A study on 3D images
}

\author{
Elena Ruiz Mediavilla, Bernardo Perea Pérez, Elena Labajo González*, \\ José Antonio Sánchez Sánchez, Enrique Dorado Fernández, Andrés Santiago Sáez
}

Escuela de Medicina Legal, Departamento de Toxicología y Legislación Sanitaria, Facultad de Medicina (Pab. 7), Universidad Complutense de Madrid, Ciudad Universitaria, S/N 28040 Madrid, España

\section{A R T I C L E I N F O}

\section{Article history:}

Received 10 April 2015

Received in revised form 11 December 2015

Accepted 23 January 2016

Available online $\mathrm{xxx}$

\section{Keywords:}

Clavicle

3D scanning

Volume

Sexual dimorphism

Spanish population

Forensic anthropology population data

\begin{abstract}
A B S T R A C T
Sexual dimorphism of the clavicle based on metric studies has been determined among different populations from different eras. Due to the need to know about sexual dimorphism in the Spanish population in order to apply the results to the field of Forensic Anthropology, a study has been carried out on a sample in the contemporary Spanish population, made up of the right and left clavicles of 50 males and 50 females. A metric, volumetric and curvature study was performed. To do so, 3D scanning was completed on the entire sample using the Picza 3D Laser Scanner, and the study was performed using reproductions. There were taken 6 metric measurements and 4 volumetric measurements using the Geomagic software, and for the study of curves, an index was calculated which related the direct length of the clavicle and its length as cast onto a surface. The data are presented for all of the variables, distinguishing between the right and left side, and there were processed using the statistical program PASW Statistics 18. The results show that the classification functions which best categorize the sample with an unique variable are volumetric, which classify the sample correctly in $94 \%$ of cases based on diaphysis volume, followed by total volume, which provides an accurate classification in $92 \%$ of all cases. The sagittal diameter at midshaft provides an accurate classification in $90 \%$ of cases and the maximum length in $88 \%$ of cases. The curvature index shows that there are no statistically significant differences by side and the only curvature index that shows significant differences by sex is the total anterior curve of the left clavicle being the males curve more pronounced. The validation study performed on a sample of 20 individuals confirms the high discriminatory power of the volume obtaining an accurate classification rate of $85-100 \%$ depending on the variable studied.
\end{abstract}

(c) 2016 Elsevier Ireland Ltd. All rights reserved

\section{Introduction}

Studying the clavicle is of particular interest, it is the only bone in the shoulder girdle which forms a synovial joint with the torso, also being the only bone which connects the upper limb to the axial skeleton [1]. Moreover, the clavicle is the last bone to complete ossification, and therefore it is of interest in terms of verifying whether this bone displays greater sexual dimorphism or asymmetry than others as a result of its late maturation.

Sexual dimorphism in the clavicle has been studied among different populations from different eras [2-12]. Most notable are the studies by Parsons, in which interest is shown not only in the metrics of the clavicle, but also in the differences in angle

\footnotetext{
* Corresponding author. Tel.: +34 913947118; fax: +34 913941606.

E-mail address: elabajo@med.ucm.es (E.L. González).
}

depending upon laterality and sex [13]. The volume of the clavicle has also been studied, though on few occasions. Most notable is the work by Singh and Jit [14] to study the volume of the clavicle, based on Archimedes' principle, calculating volume by the displacement of fluid. The study of the clavicle's asymmetry has aroused great interest in the field of Anthropology [15-21] also the study of clavicle's biomechanics in the field of Medicine [22-28], in the latter case with the objective of performing broader studies on variability in the clavicle to provide better treatment of fractures. The clavicle's curvature has also been studied by several authors [26,29-33]. New lines of research aimed at the field of geometric morphometrics began to form in order to ascertain new information about sexual dimorphism of the clavicle and to discover whether results can be improved when determining sex by combining morphology and size [19,33].

The objective of this study is to contribute classification functions which help to determine sex on the basis of the clavicle 
in the Spanish population and to indicate what percentage of accurate classification is achieved when determining sex in this manner. In a forensic environment, it is not always possible to recover the full sample, and therefore there are cases in which very few skeletal remains are available. In these cases it is necessary to obtain the greatest possible information so it is essential to create specific classification functions for a population in order to determine sex in a reliable manner, or at least with awareness of the margins of error. Because of this, it is also important to carry out new studies to attempt to find variables on the basis of which better results may be obtained, so in this study the discriminatory power of the volume variable was studied, as well. Besides not always is it possible to recover the bone on a good state of preservation and some parts could be missed or damaged so having classification functions based on certain regions could be useful to determine sex in such cases. Also it is interesting to study the extent of their sexual dimorphism to know if there is some region with a higher sexual dimorphism. It has been subject to very little study, though it improves upon the results achieved using metric variables. Another hotly debated topic has been study of the clavicle's curvature $[29,30,34]$, and therefore in this study has been attempted to verify whether the right clavicle truly does display greater curvature than the left clavicle, establishing a relationship between the length of the clavicle and the length on the surface of the curve.

\section{Material}

The study sample was obtained from two contemporary Spanish reference collections of the School of Legal Medicine of Madrid (Complutense University). The first is made up of 132 individuals born between the years 1881 and 1973 in different Spanish regions and died between the years 1975 and 1985, while the second collection is made up of 88 individuals born between the years 1941 and 1976 and died in 1996. In all, it was possible to recover the right and left clavicles of 100 individuals (50 males and 50 females) in a good state of preservation, for the study. For the validation study were taken into account those clavicles which were in good condition, but of which there was an odd number; in all, 20 clavicles (from 10 males and 10 females).

\section{Methodology}

The methodology apply to this study has been very similar to the one applied on the previous published work about sex determination by talus and radii volumes [35]. The study sample underwent three-dimensional scanning to work with the resulting 3D reproductions. To do this, a PICZA 3D laser scanner was used, the mechanism of which consists of a rotating platform in the middle of which the clavicle is placed. A laser is projected from the right side, which gradually moves from its base to a set maximum height, while the surface of the bone is scanned. In order to scan the entire clavicle, it was necessary to perform 6 surface scans (corresponding to each of the 6 perspectives or views), changing the orientation of the clavicle each time. A rotating scan, which would have made it possible to scan almost the entire clavicle, could not be performed due to its morphology, which does not allow for proper scanning of the bone's contour. A distance between points of $0.4 \mathrm{~mm}$ was selected because this was considered to be the optimal option in terms of quality/time. The time needed to scan a clavicle ranges from 40 to $50 \mathrm{~min}$. In order to join the 6 orientations together (Fig. 1), the software Pixform was used. To join 2 shells, it is necessary to manually mark 3 points in common between both orientations and then join the different meshes successively (Fig. 2). Each time 2 orientations are joined, the two shells are merged automatically to remove the

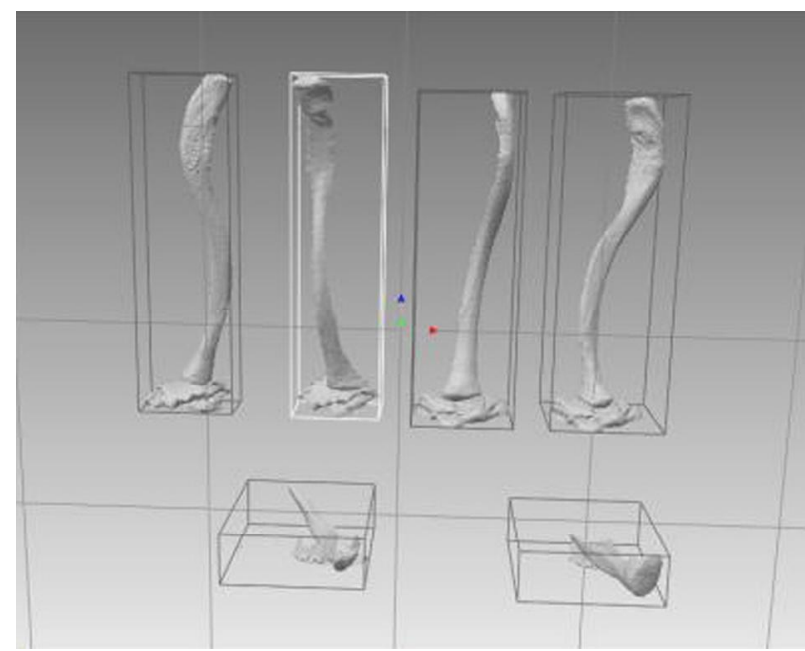

Fig. 1. Orientations of rotating and slice scans of the clavicle.

overlapped regions between shells and to stitch the neighboring boundaries together with newly added faces. The time needed to obtain the whole image depends on the expertise of the professional varying from 15 to 30 minutes. The result and accuracy of shells are still maintained after merging. Once the final 3D model is obtained it is necessary to remove spikes in order to straighten the surface by detecting and flattening single-point spikes. A low level smoothness has been chosen to not alter in excess the surface. The average of triangles for the $3 \mathrm{D}$ models has been 60.603 for female clavicles and 83.948 for male clavicles.

For the metric study, a total of 6 linear measurements were taken in the 3D reproductions of the bone. These were: maximum length, sagittal diameter at the midpoint of the diaphysis, vertical diameter at the midpoint of the diaphysis, sagittal diameter at the distal end, vertical diameter at the distal end and vertical diameter at the height of the conoid tubercle (Fig. 3 and Fig. 4). The description of the measurements is shown in Table 1. In order to take the measurements, the software Geomagic was used, which makes it possible to measure distances by positioning the two points which limit the measurement on the image.

The measurements were taken twice with a time interval of 2 months in between. A paired t-test was carried out to verify that

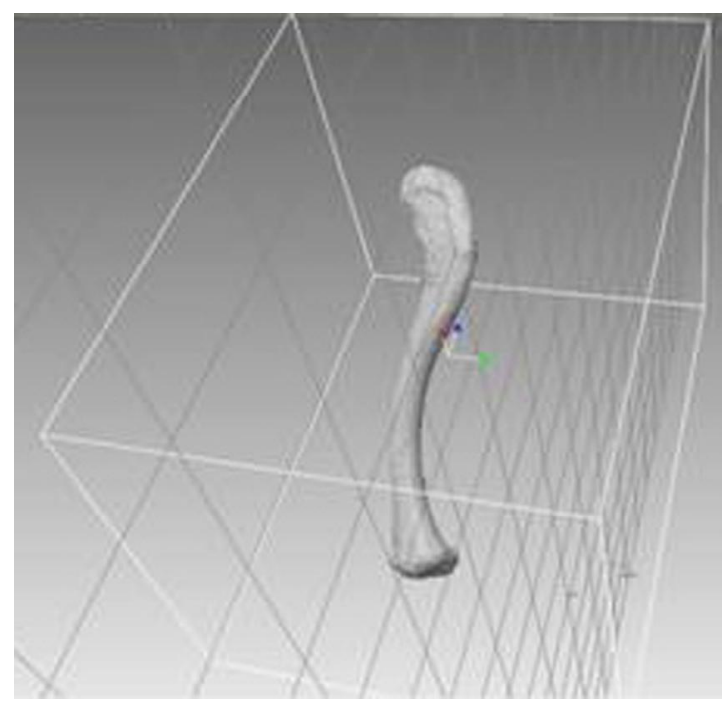

Fig. 2. Assembled orientations of the clavicle 


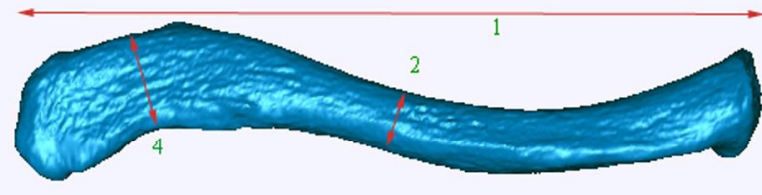

Fig. 3. Clavicle superior view. Metrical measurements 1-2-4.

there were no statistically significant differences between the two measurements and the Technical Error Measurement was calculated to study the accuracy. Then the average was calculated between the two measurements, and these were the values which were used for the later studies. Of these 6 measurements, 3 were taken (1,2 and 3) directly on the bone to verify that there were no statistically significant differences between the measurements taken on the bone and those taken in their 3D reproductions. Measurement (1) on the bone was taken using an osteometric board, whereas (2) and (3) were taken using a caliper.

The statistical studies completed were carried out using the statistical package PASW18. The first statistic that was completed was Kolmogorov-Smirnov's test to rule out that the sample did not follow a normal distribution. Because the sample was obtained from two collections an unpaired t-test was performed to check if there were statistical significant differences between them. A descriptive statistic was completed on the linear measurements to ascertain the mean, maximum and minimum values, dividing the results by sex. A paired t-test was performed to verify whether there were statistically significant differences between the variables of the right and left clavicles and to quantify the measurement error the Technical Error Measurement was calculated. An unpaired t-test was performed to verify whether there were statistically significant differences between the variables, bearing in mind sex, and last of all, a discriminatory analysis was performed to ascertain the discriminatory power of each of the variables. The discriminatory analysis was completed in two ways: first a classification tree was created, which is better visually, because it displays classification intervals, and then discriminating functions were obtained, which classify the individual as a male or female in accordance with the result which is obtained when replacing the values of the variables in the equation.

Last of all, a validation study was carried out on a sample of 20 clavicles to ascertain the rate of accurate classification by the functions obtained in the prior study.

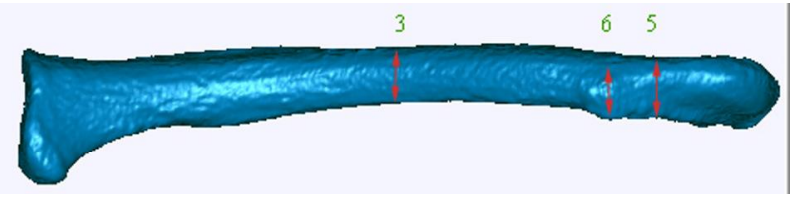

Fig. 4. Clavicle posterior view. Metrical measurements 3-5-6.

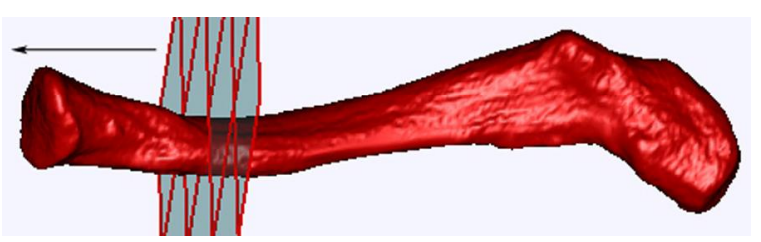

Fig. 5. Clavicle inferior view. Proximal volume limited by the impression for the costoclavicular ligament.

For the volumetric study, 4 volumes were measured: the total volume, the volume of the proximal end, the volume of the diaphysis and the volume of the distal end. The description of the measurements is shown in Table 1. In order to measure volume, the software Geomagic was used, which includes a tool that makes it possible to calculate the total volume and the volumes of parts, by carrying out plane divisions perpendicularly to the bone surface. The cutoff points are defined using two anatomical regions, the conoid tubercle (Fig. 6 and Fig. 7) and the impression for the costoclavicular ligament (Fig. 5 and Fig. 7). The same procedure and the same statistics were calculated as with the linear measurements, as well as the same validation study, on a sample of 20 clavicles (Figs. 8 and 9).

In order to study curvature, the decision was reached to calculate an index which would relate the direct length of the clavicle (linear distance between two points measured with a caliper or 3D tools) with the length of the curvature of the bone (the same length when projected onto a surface measured with a tape or 3D tools). This index was taken on two different curves, the total anterior curve and the total posterior curve. The description of the indices is shown in Table 1.

In order to calculate both the linear distance corresponding to the direct length of the clavicle and that same distance projected onto a surface, the software Geomagic was used. It includes a tool

Table 1

Description of the measurements on the clavicle.

\footnotetext{
Maximum length (1)

Sagittal diameter at the midpoint of the diaphysis (2)

Vertical diameter at the midpoint of the diaphysis (3)

Sagittal diameter at the distal end (4)

Vertical diameter at the distal end (5)

Vertical diameter at the level of the conoid tubercle (6)

Total volume (7)

Proximal end volume (8)

Diaphysis volume (9)

Distal end volume (10)

Index of the total anterior curve from

a superior view (11)

Index of the total posterior curve

from a superior view (12)
}

Distance between the most proximal and distal ends of the clavicle

Distance between the most anterior and posterior points of the clavicle at the midpoint of the diaphysis

Distance between the superior and inferior ends of the clavicle at the midpoint of the diaphysis

Distance between the most anterior and posterior points of the clavicle at its distal end, coinciding with the apex of the external curve from a cranial view

Distance between the most superior and inferior points of the clavicle at its distal end, where the sagittal diameter was taken (4)

Distance between the most superior and inferior points on the conoid tubercle

Volume of the clavicle in its entirety

Volume of the proximal end of the clavicle, up to the impression for the costoclavicular ligament (Fig. 5)

Volume of the diaphysis, up to the conoid tubercle and the impression for the costoclavicular ligament

Volume of the distal end of the clavicle, up to the conoid tubercle (Fig. 6)

Length of the clavicle's anterior curve/length projected onto surface of the clavicle's anterior curve (Fig. 8).

Positioning the clavicle into an anterior view, the linear distance was measured, as well as the distance projected onto a surface between the most proximal and distal ends of the clavicle's total anterior curve

Length of the clavicle's posterior curve/length projected onto surface of the clavicle's posterior curve (Fig. 9).

Positioning the clavicle into a posterior view, the linear distance was measured, as well as the distance projected onto a surface between the most proximal and distal ends of the clavicle's total posterior curve 


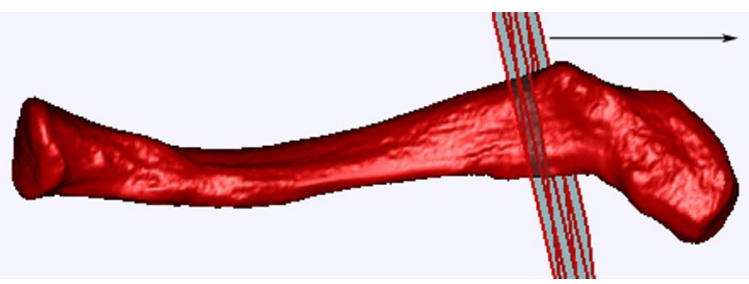

Fig. 6. Clavicle inferior view. Distal volume limited by conoid tubercle.

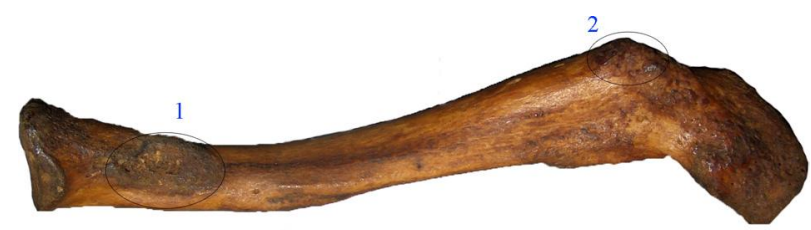

Fig. 7. Clavicle inferior view. (1) impression for the costoclavicular ligament. (2) conoid tubercle.

which makes it possible to calculate a distance between two points in both ways: in a linear manner and when projected onto a surface.

A descriptive statistical study was performed to show the medium values of indices separating the sample by sex and side. A paired $t$-test was performed to verify if there were statistically significant differences by side and an unpaired $t$-test to verify if there were statistically significant differences by sex.

A second observer measured the maximum length, the proximal end volume and the distal end volume on a sample of 20 clavicles. A paired $t$-test was performed to check if there were statistically significant differences between the measures taken by both observers.

\section{Results}

The results found in the Kolmogorov-Smirnov test caused us to reject the hypothesis that the sample was not of a normal distribution $(p>0.05)$, and therefore the later studies were performed using parametric tests. There were no statistically significant differences between collections $(t>-0.801 p>0.425)$ so the sample was treated as a whole.

The results found in the paired t-tests show that there are no statistically significant differences between the two measurements taken on the bone and the two measurements taken on the $3 \mathrm{D}$ reproduction $(p>0.05)$. The relative values of the Technical Error Measurement calculation shown in Table 2 are considered acceptable [37,38]. No statistically significant differences were found between the same measurements taken on the bone and the $3 \mathrm{D}$ reproduction, confirming the reliability of the measurements. The study was continued by calculating an average of the two measurements which had been taken on the same variable so as to

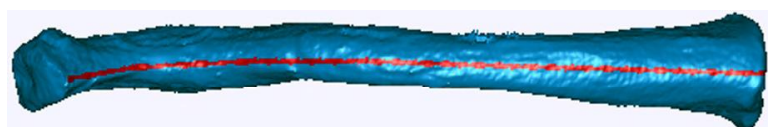

Fig. 8. Clavicle anterior view. Total anterior curve.

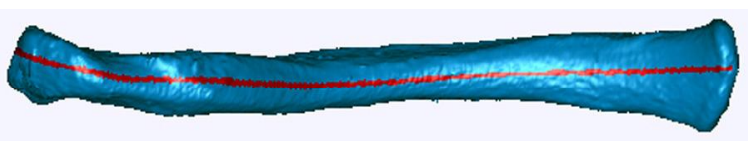

Fig. 9. Clavicle posterior view. Total posterior curve.

minimize errors. No statistically significant differences are found between the same measurements taken by the two observers $(p>0.05)$

The results describing the metric and volumetric variables are provided in Table 3. This table also shows the results found in the paired t-test to ascertain whether there are statistically significant differences between right and left clavicles. The results show that the males display higher values for all of the variables, just as the right clavicles do, displaying higher values for all of the variables with the exception of maximum length and the sagittal diameter at distal end in males. These side differences are statistically significant in all cases with the exception of the metrical measurements of the distal end and the right diaphysis volume in males. The distribution of side differences in length is shown in Fig. 10.

The independent two-sample $t$-test showed how the differences between males and females were statistically significant $(p<0.01)$ for the metric and volumetric variables, and therefore intervals were calculated that were determined using classification trees which are shown in Table 4. Classification functions were also calculated and are shown in Tables 5 and 6 respectively, indicating the percentage of accurate classification using each of the variables. Both methods can be used interchangeably to classify a sample but best results are obtained using the classification intervals. The best variables on the basis of which classification functions are determined with the highest rate of accurate classification of cases are right diaphysis volume, which provides an accurate classification in $94 \%$ of all cases, followed by the total volume (92\% of all cases classified accurately) and then the right sagittal diameter at midshaft ( $90 \%$ of all cases classified accurately) and right maximum length ( $88 \%$ of all cases classified accurately). The results determined on the basis of proximal volume and distal volume are better than those obtained with the metric variables of the distal end. The combination of the different volumetric variables does not improve the results obtained using the variables independently. The combination of the 6 different metrical measurements correctly classifies the $95 \%$ of the sample. The best results are obtained combining all variables, except total volume, correctly classifying the $96 \%$ of the sample.

Table 2

Relative values of the intra-evaluator TEM calculation (\%).

\begin{tabular}{|c|c|c|c|c|c|c|c|c|c|c|}
\hline & & $\begin{array}{l}\text { Maximum } \\
\text { length }\end{array}$ & $\begin{array}{l}\text { Sagittal } \\
\text { diameter } \\
\text { midshaft }\end{array}$ & $\begin{array}{l}\text { Vertical } \\
\text { diameter } \\
\text { midshaft }\end{array}$ & $\begin{array}{l}\text { Sagittal } \\
\text { diameter } \\
\text { distal end }\end{array}$ & $\begin{array}{l}\text { Vertical } \\
\text { diameter } \\
\text { distal end }\end{array}$ & $\begin{array}{l}\text { Vertical } \\
\text { diameter lateral } \\
\text { tubercle }\end{array}$ & $\begin{array}{l}\text { Proximal } \\
\text { volume }\end{array}$ & $\begin{array}{l}\text { Diaphysis } \\
\text { volume }\end{array}$ & $\begin{array}{l}\text { Distal } \\
\text { volume }\end{array}$ \\
\hline \multirow[t]{3}{*}{ Dry bone } & Right & 0.151 & 0.938 & 2.154 & & & & & & \\
\hline & Left & 0.172 & 1.337 & 1.611 & & & & & & \\
\hline & & & & & 1.47 & 3.463 & 2.499 & 4.795 & 4.663 & 2.833 \\
\hline \multirow[t]{2}{*}{ 3D image } & Right & 0.143 & 2.081 & 2.978 & 1.715 & 3.265 & 2.559 & 4.614 & 4.559 & 3.178 \\
\hline & Left & 0.101 & 2.1 & 2.906 & & & & & & \\
\hline
\end{tabular}


Table 3

Statistics describing the clavicle linear measurements $(\mathrm{mm}$.$) and volumes \left(\mathrm{cm}^{3}\right)$ in males and females and side differences.

\begin{tabular}{|c|c|c|c|c|c|c|c|c|c|}
\hline \multirow[b]{2}{*}{ Clavicle } & \multirow[b]{2}{*}{ Side } & \multicolumn{4}{|c|}{ Male } & \multicolumn{4}{|c|}{ Female } \\
\hline & & $N$ & Mean & SD & $\mathrm{p}^{\mathrm{a}}$ & $N$ & Mean & SD & $\mathrm{p}^{\mathrm{a}}$ \\
\hline \multirow[t]{2}{*}{ Maximum length } & $\mathrm{R}$ & 50 & 149.97 & 10.19 & $0.011^{*}$ & 50 & 131.84 & 7.18 & $0.000^{* *}$ \\
\hline & $\mathrm{L}$ & 50 & 151.55 & 9.17 & & 50 & 133.85 & 6.41 & \\
\hline \multirow[t]{2}{*}{ Sagittal diameter midshaft } & $\mathrm{R}$ & 50 & 13.63 & 1.34 & $0.000^{* *}$ & 50 & 11.12 & 1.16 & $0.000^{* *}$ \\
\hline & $\mathrm{L}$ & 50 & 12.9 & 1.22 & & 50 & 10.42 & 1.01 & \\
\hline \multirow[t]{2}{*}{ Vertical diameter midshaft } & $\mathrm{R}$ & 50 & 10.58 & 0.92 & $0.006^{* *}$ & 50 & 8.64 & 0.99 & $0.029^{*}$ \\
\hline & $\mathrm{L}$ & 50 & 10.26 & 1.05 & & 50 & 8.43 & 0.88 & \\
\hline \multirow[t]{2}{*}{ Sagittal diameter distal end } & $\mathrm{R}$ & 50 & 18.99 & 2.35 & 0.526 & 50 & 16.18 & 2.02 & 0.381 \\
\hline & $\mathrm{L}$ & 50 & 19.16 & 2.23 & & 50 & 16.01 & 2.21 & \\
\hline \multirow[t]{2}{*}{ Vertical diameter distal end } & $\mathrm{R}$ & 50 & 9.74 & 1.5 & 0.138 & 50 & 8.27 & 1.43 & 0.156 \\
\hline & $\mathrm{L}$ & 50 & 9.46 & 1.73 & & 50 & 8.04 & 1.49 & \\
\hline \multirow[t]{2}{*}{ Vertical diameter lateral tubercle } & $\mathrm{R}$ & 50 & 11.62 & 1.73 & 0.165 & 50 & 10.25 & 1.58 & 0.536 \\
\hline & $\mathrm{L}$ & 50 & 11.39 & 1.95 & & 50 & 10.15 & 2.01 & \\
\hline \multirow[t]{2}{*}{ Total volume } & $\mathrm{R}$ & 50 & 25.62 & 4.1 & $0.001^{* *}$ & 50 & 16.06 & 2.86 & $0.000^{* *}$ \\
\hline & $\mathrm{L}$ & 50 & 24.68 & 4.15 & & 50 & 15.28 & 3.12 & \\
\hline \multirow[t]{2}{*}{ Proximal volume } & $\mathrm{R}$ & 50 & 7.91 & 2.23 & $0.018^{*}$ & 50 & 5.35 & 1.42 & $0.034^{*}$ \\
\hline & $\mathrm{L}$ & 50 & 7.5 & 2.01 & & 50 & 5.09 & 1.45 & \\
\hline \multirow[t]{2}{*}{ Diaphysis volume } & $\mathrm{R}$ & 50 & 9.92 & 1.61 & 0.249 & 50 & 5.75 & 1.12 & $0.034^{*}$ \\
\hline & $\mathrm{L}$ & 50 & 9.74 & 1.81 & & 50 & 5.5 & 1.18 & \\
\hline \multirow[t]{2}{*}{ Distal volume } & $\mathrm{R}$ & 50 & 7.79 & 1.61 & $0.016^{*}$ & 50 & 4.96 & 1.07 & $0.013^{*}$ \\
\hline & $\mathrm{L}$ & 50 & 7.44 & 1.56 & & 50 & 4.7 & 1.23 & \\
\hline
\end{tabular}

${ }^{a}$ Level of significance of the paired-t test to study side-based differences ${ }^{*} p<0.05,{ }^{* *} p<0.01$.

The results for the curvature indices are shown in Table 7. Index values more distant from 1 indicate a greater curvature. The results show that posterior curve (Fig. 6) is greater than the anterior (Fig. 5) being the differences statistically significant $(p<0.05)$. The medium values of the posterior curve index shows that right side is more curved than left and that females posterior curve is greater than males but these differences are not statistically significant. The medium values of the anterior curve index shows that right side is more curved than left in females but not in males, being both differences not statistically significant. In this case males curve is greater than females being the differences statistically significant on the left side. 70 out of 100 clavicles have right clavicle shorter than the left ( 33 males and 37 females). Although the differences are not statistically significant 12 out of 33 males have a greater right anterior and posterior curve, 6 out of 33 have a greater right posterior curve and 7 out of 33 have a greater right anterior curve. 10 out of 37 females have a greater right anterior and posterior

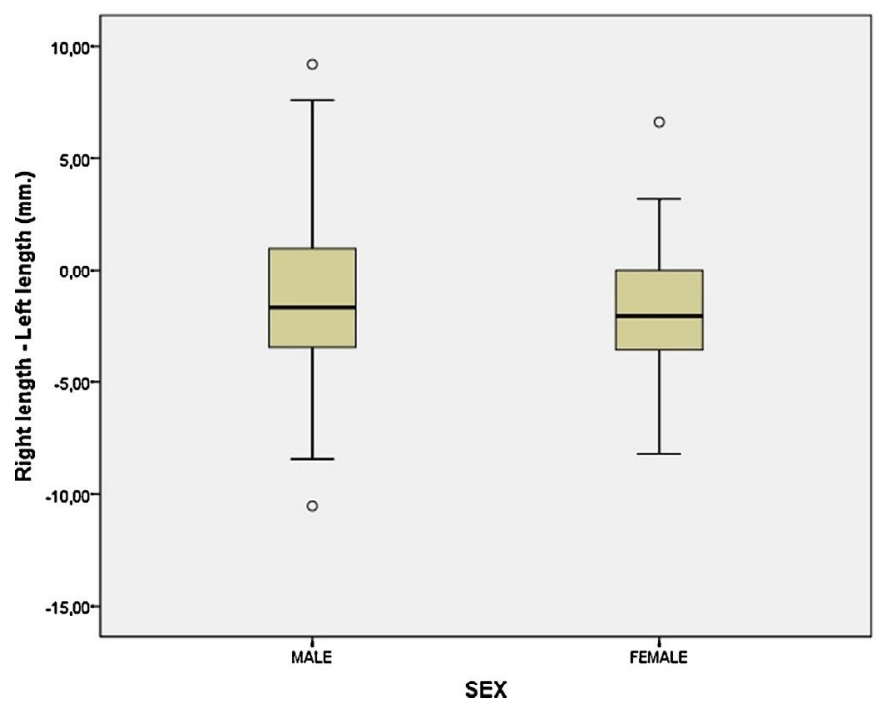

Fig. 10. Differences between right and left clavicle length (mm.). curve, 10 out of 37 have a greater right posterior curve and 13 out of 37 have a greater right anterior curve. 30 out of 100 clavicles have left clavicle shorter than the right (17 males and 13 females). 5 out of 17 males have a greater anterior and posterior curve, 2 out of 17 have a greater posterior curve and 4 out of 17 have a greater anterior curve. 3 out of 13 females have a greater anterior and posterior curve, 2 out of 13 have a greater posterior curve and 4 out of 13 have a greater anterior curve.

The results of the validation test performed on a sample of 20 clavicles ( 10 males and 10 females) are shown in Table 8 . The variables which best classified the sample were that of total volume and diaphysis volume, which accurately classified $100 \%$ of the cases. With the metric variables, the best results are achieved using indistinctively the maximum length, the sagittal and vertical diameters at midshaft, which accurately classified $90 \%$ of the cases. The results obtained confirm the reliability of applying these formulas to Spanish population.

\section{Discussion}

One of the advantages of 3D scanning the sample is that a reproduction of the bone is obtained, as a whole, it constitutes a digital library that includes a digitized copy of the original sample which is very useful if the original is lost or damaged. It can also be accessed from any location which allows doing comparative studies with other populations without moving and their study is clean, fast and reliable. In this study has offered the opportunity to calculate the volume automatically and easily which is a big step because the limitation of calculating it in a reliable manner had not allowed studying its discriminatory power.

The results found show that the clavicle can be used to determine sex quite reliably, achieving rates of accurate classification of approximately $96 \%$. Most of the studies which analyze the discriminatory power of the clavicle have done so on the basis of metric studies, finding results which ranged from $85 \%$ to $93 \%$ depending on the population studied using maximum length [2$8,10-12]$. One of the advantages of presenting classification intervals for each variable is that it is possible to know the overlapping region where is difficult to assign sex with reliability. This fact is important for practitioners in terms of reaching a decision. 
Table 4

Classification intervals for clavicle metrical measurements $(\mathrm{mm})$ and volumes $\left(\mathrm{cm}^{3}\right)$.

\begin{tabular}{|c|c|c|c|c|c|}
\hline Clavicle & Side & Classification interval & $\% \mathrm{M}^{\mathrm{a}}$ & $\% \mathrm{~F}^{\mathrm{b}}$ & $\% \mathrm{CC}^{\mathrm{c}}$ \\
\hline \multirow[t]{5}{*}{ Maximum length } & $\mathrm{R}$ & $<=144.97$ & 18.3 & 81.7 & 88 \\
\hline & & $>144.97$ & 97.5 & 2.5 & \\
\hline & $\mathrm{L}$ & $<=144.412$ & 20 & 80 & \\
\hline & & (144.412-149.86] & 80 & 20 & 86 \\
\hline & & $>149.86$ & 100 & 0 & \\
\hline \multirow[t]{5}{*}{ Sagittal diameter midshaft } & $\mathrm{R}$ & $<=12.278$ & 22 & 78 & \\
\hline & & (12.278-12.675] & 30 & 70 & 90 \\
\hline & & $>12.675$ & 90 & 10 & \\
\hline & $\mathrm{L}$ & $<=11.58$ & 12 & 88 & 88 \\
\hline & & $>11.58$ & 88 & 12 & \\
\hline \multirow[t]{6}{*}{ Vertical diameter midshaft } & $\mathrm{R}$ & $<=8.695$ & 3.3 & 96.7 & \\
\hline & & (8.695-10.092] & 40 & 60 & 84 \\
\hline & & $>10.092$ & 92.5 & 7.5 & \\
\hline & $\mathrm{L}$ & $<=8.67$ & 7.5 & 92.5 & \\
\hline & & $(8.67-10.075]$ & 63.3 & 36.7 & 84 \\
\hline & & $>10.075$ & 93.3 & 6.7 & \\
\hline \multirow[t]{4}{*}{ Sagittal diameter distal end } & $\mathrm{R}$ & $<=18.432$ & 26.7 & 73.3 & 78 \\
\hline & & $>18.432$ & 85 & 15 & \\
\hline & $\mathrm{L}$ & $<=17.67$ & 22 & 78 & 78 \\
\hline & & $>17.67$ & 78 & 22 & \\
\hline \multirow[t]{5}{*}{ Vertical diameter distal end } & $\mathrm{R}$ & $<=9.238$ & 28 & 72 & 72 \\
\hline & & $>9.238$ & 72 & 28 & \\
\hline & $\mathrm{L}$ & $<=7.617$ & 23.3 & 76.7 & \\
\hline & & (7.617-9.682] & 50 & 50 & 66 \\
\hline & & $>9.682$ & 76.7 & 23.3 & \\
\hline \multirow[t]{4}{*}{ Vertical diameter conoid tubercle } & $\mathrm{R}$ & $<=11.276$ & 31.7 & 68.3 & 72 \\
\hline & & $>11.276$ & 77.5 & 22.5 & \\
\hline & $\mathrm{L}$ & $<=10.768$ & 32 & 68 & 68 \\
\hline & & $>10.768$ & 68 & 32 & \\
\hline \multirow[t]{5}{*}{ Total volume } & $\mathrm{R}$ & $<=17.882$ & 0 & 100 & \\
\hline & & $(17.882-20.23]$ & 40 & 60 & 92 \\
\hline & & $>20.23$ & 92 & 8 & \\
\hline & $\mathrm{L}$ & $<=18.52$ & 8 & 92 & 92 \\
\hline & & $>18.52$ & 92 & 8 & \\
\hline \multirow[t]{5}{*}{ Proximal volume } & $\mathrm{R}$ & $<=6.689$ & 23.3 & 76.7 & 82 \\
\hline & & $>6.689$ & 90 & 10 & \\
\hline & $\mathrm{L}$ & $<=4.36$ & 5 & 95 & \\
\hline & & $(4.36-6.386]$ & 37.5 & 62.5 & 78 \\
\hline & & $>6.386$ & 85 & 15 & \\
\hline \multirow[t]{5}{*}{ Diaphysis volume } & $\mathrm{R}$ & $<=6.322$ & 0 & 100 & \\
\hline & & $(6.322-7.513]$ & 30 & 70 & 94 \\
\hline & & $>7.513$ & 94 & 6 & \\
\hline & $\mathrm{L}$ & $<=6.938$ & 8 & 92 & 92 \\
\hline & & $>6.938$ & 92 & 8 & \\
\hline \multirow[t]{5}{*}{ Distal volume } & $\mathrm{R}$ & $<=6.02$ & 14 & 86 & 86 \\
\hline & & $>6.02$ & 86 & 14 & \\
\hline & $\mathrm{L}$ & $<=4.643$ & 3.3 & 96.7 & \\
\hline & & $(4.643-6.255]$ & 40 & 60 & 84 \\
\hline & & $>6.255$ & 92.5 & 7.5 & \\
\hline
\end{tabular}

a Percentage of males on each interval.

b Percentage of females on each interval.

c Percentage of correct classified.

For comparison with other populations, the main measurement that could be compared was that of maximum length, the average of the Spanish population being below the others, with the exception of the populations of India, Guatemala, Nepal, Gujarat and Iran, in which the average values are higher in the Spanish population $[2-8,10,13]$. The sagittal and vertical diameters at midshaft could be compared with three populations, American Black, American White [6] and Cretans [9] being greater on the first and more similar with the measures of the third group. Comparing with American White sagittal diameter is greater in Spanish population but vertical diameter value is lesser. If the length cutoff values of these populations are used to assign sex in the present sample the accuracy rates are $75-80 \%$ in case of using the American Black cut-off values, $82-85 \%$ using the American White cut-off values, $77-84 \%$ using the Iranian cut-off values, $87-88 \%$ using the modern English clavicles cut-off values and $88-89 \%$ using the cutoff values for Greek population. Using the cut-off values for
American Black sagittal diameter the accuracy rate is $69-80 \%$, for American Black vertical diameter is $79-85 \%$, for the American White sagittal diameter is $84-86 \%$, and for American White vertical diameter is $79-85 \%$. The variability in the results depending on the population data used confirms the need of having specific functions for each population to minimize the errors determining sex.

For volume, only one study has been found [14], completed on the population of India, in which the volumes of the clavicle in males ranged from 9.3 to $33.9 \mathrm{ml}$ on the right side and from 9.4 to $33 \mathrm{ml}$ on the left, and in females form 7.5 to $20.40 \mathrm{ml}$ and from 7 to $20 \mathrm{ml}$, for the right and left sides, respectively. In the case of the Spanish population, the values calculated vary among males from 18 to $39 \mathrm{ml}$ on the right side and from 16.824 to $36.815 \mathrm{ml}$ on the left side, and in females from 9.996 to $26.18 \mathrm{ml}$ on the right side, and from 10.298 to $25.105 \mathrm{ml}$ on the left side. The values in the Spanish population are higher than those of the Indian population 
Table 5

Classification functions for clavicle metrical measurements (mm.).

\begin{tabular}{|c|c|c|c|c|}
\hline Clavicle & Side & Classification function & Wilk's $\lambda$ & $\% \mathrm{CC}^{\mathrm{a}}$ \\
\hline \multirow[t]{3}{*}{ Maximum length (1) } & $\mathrm{R}$ & $\begin{array}{l}0.233(1)-32.897>0 \text { Male } \\
<0 \text { Female }\end{array}$ & 0.481 & $80 \%$ Males \\
\hline & $\mathrm{L}$ & $0.282(1)-40.353>0$ Male & 0.439 & $80 \%$ Males \\
\hline & & $<0$ Female & & $90 \%$ Females \\
\hline \multirow{4}{*}{$\begin{array}{l}\text { Sagittal diameter } \\
\text { midshaft (2) }\end{array}$} & $\mathrm{R}$ & $1.592(2)-19.703>0$ Male & 0.496 & $78 \%$ Males \\
\hline & & $<0$ Female & & $78 \%$ Females \\
\hline & $\mathrm{L}$ & $1.971(2)-22.986>0$ Male & 0.444 & $84 \%$ Males \\
\hline & & $<0$ Female & & $88 \%$ Females \\
\hline \multirow{4}{*}{$\begin{array}{l}\text { Vertical diameter } \\
\text { midshaft (3) }\end{array}$} & $\mathrm{R}$ & $2.135(3)-20.523>0$ Male & 0.486 & $84 \%$ Males \\
\hline & & $<0$ Female & & $84 \%$ Females \\
\hline & $\mathrm{L}$ & $1.948(3)-18.203>0$ Male & 0.523 & $80 \%$ Males \\
\hline & & $<0$ Female & & $86 \%$ Females \\
\hline \multirow{4}{*}{$\begin{array}{l}\text { Sagittal diameter distal } \\
\text { end }(4)\end{array}$} & $\mathrm{R}$ & $0.583(4)-10.256>0$ Male & 0.706 & 74\% Males \\
\hline & & $<0$ Female & & $78 \%$ Females \\
\hline & $\mathrm{L}$ & $0.639(4)-11.241>0$ Male & 0.661 & $80 \%$ Males \\
\hline & & $<0$ Female & & $76 \%$ Females \\
\hline \multirow{4}{*}{$\begin{array}{l}\text { Vertical diameter } \\
\text { distal end (5) }\end{array}$} & $\mathrm{R}$ & $0.691(4)-6.218>0$ Male & 0.794 & $72 \%$ Males \\
\hline & & $<0$ Female & & $64 \%$ Females \\
\hline & $\mathrm{L}$ & $0.542(4)-4.741>0$ Male & 0.836 & $60 \%$ Males \\
\hline & & $<0$ Female & & $70 \%$ Females \\
\hline \multirow{4}{*}{$\begin{array}{l}\text { Vertical diameter } \\
\text { lateral tubercle }(6)\end{array}$} & $\mathrm{R}$ & $0.5(4)-5.466>0$ Male & 0.851 & $66 \%$ Males \\
\hline & & $<0$ Female & & $70 \%$ Females \\
\hline & $\mathrm{L}$ & $0.317(4)-3.415>0$ Male & 0.909 & $68 \%$ Males \\
\hline & & $<0$ Female & & $66 \%$ Females \\
\hline \multirow[t]{2}{*}{$1+2+3+4+5+6$} & $\mathrm{~L}$ & $\begin{array}{l}0.195(1)+1.632(2)+1.447(3)+0.377(4)+0.6(5)-0.76(6) \\
-64.125>0 \text { Male }<0 \text { Female }\end{array}$ & 0.258 & 94\% Males \\
\hline & & & & $96 \%$ Females \\
\hline \multirow[t]{2}{*}{$1+2+3$} & $\mathrm{~L}$ & $0.225(1)+1.429(2)+1.317(3)-61.079>0$ Male $<0$ Female & 0.283 & $94 \%$ Males \\
\hline & & & & $94 \%$ Females \\
\hline \multirow[t]{2}{*}{$1+2+3$} & $\mathrm{R}$ & $0.229(1)+1.034(2)+1.762(3)-62.062>0$ Male $<0$ Female & 0.278 & $92 \%$ Males \\
\hline & & & & $94 \%$ Females \\
\hline \multirow[t]{2}{*}{$1 L+2 L+3 R$} & $\mathrm{R}+\mathrm{L}$ & $0.253(1)+1.196(2)+1.677(3)-66.093>0$ Male $<0$ Female & 0.268 & $94 \%$ Males \\
\hline & & & & 94\% Females \\
\hline
\end{tabular}

${ }^{\text {a }}$ Percentage of correct classified.

Table 6

Classification functions for clavicle volumes $\left(\mathrm{cm}^{3}\right)$.

\begin{tabular}{|c|c|c|c|c|}
\hline Clavicle & Side & Classification function & Wilk's $\lambda$ & $\% \mathrm{CC}^{\mathrm{a}}$ \\
\hline \multirow[t]{2}{*}{ Total volume (7) } & $\mathrm{R}$ & $\begin{array}{l}0.766(7)-15.959>0 \text { Male } \\
<0 \text { Female }\end{array}$ & 0.349 & $\begin{array}{l}90 \% \text { Males } \\
94 \% \text { Females }\end{array}$ \\
\hline & $\mathrm{L}$ & $\begin{array}{l}0.697(7)-13.928>0 \text { Male } \\
<0 \text { Female }\end{array}$ & 0.374 & $\begin{array}{l}88 \% \text { Males } \\
94 \% \text { Females }\end{array}$ \\
\hline \multirow[t]{2}{*}{ Proximal volume (8) } & $\mathrm{R}$ & $\begin{array}{l}0.733(8)-4.864>0 \text { Male } \\
<0 \text { Female }\end{array}$ & 0.676 & $\begin{array}{l}76 \% \text { Males } \\
90 \% \text { Females }\end{array}$ \\
\hline & $\mathrm{L}$ & $\begin{array}{l}0.782(8)-4.925>0 \text { Male } \\
<0 \text { Female }\end{array}$ & 0.676 & $\begin{array}{l}70 \% \text { Males } \\
86 \% \text { Females }\end{array}$ \\
\hline \multirow[t]{2}{*}{ Diaphysis volume (9) } & $\mathrm{R}$ & $\begin{array}{l}2.165(9)-16.954>0 \text { Male } \\
<0 \text { Female }\end{array}$ & 0.303 & $\begin{array}{l}\text { 92\% Males } \\
94 \% \text { Females }\end{array}$ \\
\hline & $\mathrm{L}$ & $\begin{array}{l}1.823(9)-13.888>0 \text { Male } \\
<0 \text { Female }\end{array}$ & 0.337 & $\begin{array}{l}88 \% \text { Males } \\
96 \% \text { Females }\end{array}$ \\
\hline \multirow[t]{2}{*}{ Distal volume (10) } & $\mathrm{R}$ & $\begin{array}{l}1.511(10)-9.633>0 \text { Male } \\
<0 \text { Female }\end{array}$ & 0.479 & $\begin{array}{l}76 \% \text { Males } \\
90 \% \text { Females }\end{array}$ \\
\hline & $\mathrm{L}$ & $\begin{array}{l}1.391(10)-8.438>0 \text { Male } \\
<0 \text { Female }\end{array}$ & 0.507 & $\begin{array}{l}80 \% \text { Males } \\
90 \% \text { Females }\end{array}$ \\
\hline $9 R+7 R+6 L$ & $\mathrm{R}+\mathrm{L}$ & $\begin{array}{l}1.613(9 \mathrm{R})+0.461(7 \mathrm{R})-0.452(6 \mathrm{I})-17.372>0 \text { Male } \\
<0 \text { Female }\end{array}$ & 0.271 & $\begin{array}{l}88 \% \text { Males } \\
96 \% \text { Females }\end{array}$ \\
\hline $9 R+2 L+6 L$ & $\mathrm{R}+\mathrm{L}$ & $\begin{array}{l}1.932(9 \mathrm{R})+0.985(2 \mathrm{~L})-0.403(6 \mathrm{~L})-22.272 \\
>0 \text { Male } \\
<0 \text { Female }\end{array}$ & 0.282 & $\begin{array}{l}\text { 90\% Males } \\
96 \% \text { Females }\end{array}$ \\
\hline $\begin{array}{l}1 \mathrm{R}+1 \mathrm{~L}+2 \mathrm{R}+2 \mathrm{~L}+3 \mathrm{R}+ \\
3 \mathrm{~L}+4 \mathrm{R}+4 \mathrm{~L}+5 \mathrm{R}+ \\
5 \mathrm{~L}+6 \mathrm{R}+6 \mathrm{~L}+8 \mathrm{R}+ \\
8 \mathrm{~L}+9 \mathrm{R}+9 \mathrm{~L}+10 \mathrm{R}+10 \mathrm{~L}\end{array}$ & $\mathrm{R}+\mathrm{L}$ & $\begin{array}{l}-0.017(1 \mathrm{R})+0.230(1 \mathrm{~L})+0.063(2 \mathrm{R})+1.218(2 \mathrm{~L})+0.432(3 \mathrm{R}) \\
+0.841(3 \mathrm{~L})-0.294(4 \mathrm{R})+0.58(4 \mathrm{~L})+0.259(5 \mathrm{R})+0.477(5 \mathrm{~L}) \\
+0.508(6 \mathrm{R})-0.942(6 \mathrm{~L})+0.183(8 \mathrm{R})+0.06(8 \mathrm{~L})+1.146(9 \mathrm{R}) \\
-0.229(9 \mathrm{~L})+0.125(10 \mathrm{R})-0.794(10 \mathrm{~L})-65.242\end{array}$ & & $96 \%$ Males \\
\hline $8 L+9 R+9 L+10 R+10 L$ & & $\begin{array}{l}>0 \text { Male } \\
<0 \text { Female }\end{array}$ & 0.231 & $96 \%$ Females \\
\hline
\end{tabular}

\footnotetext{
${ }^{\text {a }}$ Percentage of correct classified.
} 
Table 7

Curvature indices.

\begin{tabular}{|c|c|c|c|c|c|c|c|c|}
\hline \multirow[b]{2}{*}{ Clavicle } & \multirow[b]{2}{*}{ Side } & \multicolumn{3}{|c|}{ MALE } & \multicolumn{3}{|c|}{ FEMALE } & \multirow[b]{2}{*}{$\mathrm{p}^{\mathrm{a}}$} \\
\hline & & $\mathrm{N}$ & Mean & SD & $\mathrm{N}$ & Mean & SD & \\
\hline \multirow[t]{2}{*}{ Total posterior curve } & $\mathrm{R}$ & 50 & 0.8972 & 0.024 & 50 & 0.8946 & 0.022 & 0.574 \\
\hline & $\mathrm{L}$ & 50 & 0.8988 & 0.024 & 50 & 0.8949 & 0.02 & 0.390 \\
\hline \multirow[t]{2}{*}{ Total anterior curve } & $\mathrm{R}$ & 50 & 0.9455 & 0.019 & 50 & 0.9517 & 0.021 & 0.12 \\
\hline & L & 50 & 0.9446 & 0.025 & 50 & 0.9534 & 0.013 & $0.032^{*}$ \\
\hline
\end{tabular}

${ }^{\text {a }}$ Level of significance of the unpaired-t test to study sex-based differences ${ }^{*} p<0.05$.

Table 8

Validation test

\begin{tabular}{llllll}
\hline Clavicle & $\begin{array}{l}\text { Maximum } \\
\text { length }\end{array}$ & $\begin{array}{l}\text { Sagittal diameter } \\
\text { midshaft }\end{array}$ & $\begin{array}{l}\text { Vertical diameter } \\
\text { midshaft }\end{array}$ & $\begin{array}{l}\text { Sagittal diameter } \\
\text { distal end }\end{array}$ & $\begin{array}{l}\text { Vertical diameter } \\
\text { distal end }\end{array}$ \\
\hline $\mathrm{CC}^{1}$ & 90 & 90 & 90 & 75 & 70 \\
Clavicle & Total volume & Proximal volume & Diaphysis volume & Distal volume \\
$\mathrm{CC}^{1}$ & 100 & 85 & 100 & 90 & 70 \\
\hline
\end{tabular}

$\mathrm{CC}^{1}$ percentage of individuals correctly classified with each variable.

studied, coinciding with the differences which were also found in the metric measurements, and therefore specific population studies are needed to be able to discriminate sex with a higher success rate.

It has been observed that both the proximal region and the distal region of the clavicle offer similar results when one intends to determine sex on the basis of its volume, although better results are obtained with the distal volume. The volume of the diaphysis is one of the 3 regions which provide the best results. Of the metric variables, those taken at the midpoint of the diaphysis discriminate better than the three at the distal end, the best being the sagittal diameter at midshaft. The results obtained determining sex by the three metric measurements at the distal end are not as good as the results obtained by the distal volume, so this last variable is more reliable to sex determination. Considering the results obtained by volume and metrics the diaphysis appear to be the most dimorphic part of the clavicle.

There is a set of variables which could be influencing, to a greater or lesser degree, the differences which are found between males and females: the amount of muscle, the level of physical activity performed and the level of bone quantity-quality. One must bear in mind that the different regions in the clavicle display different muscular and ligament entry points, and therefore each region is subject to different forces. At the distal end, the acromyoclavicular joint is kept in place by 4 ligaments: the superior ligament, inferior ligament, conoid ligament and trapezoidal ligament. The conoid ligament keeps the angle formed by the two bones (clavicle-scapula) from opening and the trapezoidal ligament keeps it from closing [36]. Located in the diaphysis is the subclavius muscle, which leads from the inferior face of the clavicle (central portion) to the superior face of the first rib and the first costal cartilage. Its role is to make the clavicle move downward, and it is an active ligament in the sternoclavicular joint [36]. Also entering into the diaphysis is the occipital sternocleidomastoid muscle, which joins the cranium with the internal part of the clavicle and the sternum. If the cranium is the fixed point, it raises the sternum and the internal part of the clavicle; it therefore provides upward lift. The trapezium has three shafts and it is the superior shaft which ends at the posterior edge of the clavicle (external third) and the acromion. The superior trapezium is required in excess when it is exerted using the superior limb in suspension, as when typing [36]. The pectoralis major muscle originates in the clavicle (in the internal $2 / 3$ of the anterior edge), all along the sternum and the costal cartilage. If the fixed point is the rib cage, the set of fibers perform adduction of the arm and its internal rotation. This muscle is required, for example, when hugging or in brachial suspension [36]. The deltoid muscle is divided into three shafts and the anterior shaft is the one that enters into the clavicle (external third of the anterior edge). The anterior shaft performs the antepulsion and internal rotation of the arm, the medial shaft performs abduction of the arm, and the posterior shaft performs the arm's retropulsion [36].

Between males and females there are differences at the muscular level, and considerable variation is found between the lengths and diameters of the fibers in adults. The skeletal muscular fibers grow in length and diameter from birth until adulthood, with a fivefold increase in their size during this time period. The activity performed by the individual it is also influencing. The increase in muscle size due to resistance training leads to an increase in the diameter of fibers more than in their number. This number is determined genetically and varies from one person to the next. The diameter of the fibers may also be increased by resistance training and also the bone responds dynamically to the presence or absence of forces with changes in size, shape and density. It appears that the larger the forces and loads which regularly act are, the more dramatic the increase in the bone's mineralization is. It is the magnitude of the skeleton's load more than the frequency of bearing loads which is related with the bone's mass [39].

Asymmetry in the clavicle with respect to the greater length that left clavicles appear to display has been described in different populations. Olivier had already described it in 1951 [29]. Mays et al. [17], Auerbach and Raxter [18] concluded that the asymmetry in the clavicle was due above all to differences in activity patterns and in behavior in bearing loads, with the diameters measured on the diaphysis being more sensitive than length to the effect of bearing loads. The sole path for development of the clavicle may also play a role in the atypical pattern of asymmetry observed in the clavicle. Auerbach and Raxter [18] also described the right clavicles asymmetry in the diaphysis, the parameters studied in the latter being greater than in the right clavicles.

Asymmetry was also studied in fetal bones by Mohsin et al. [20], who did not find variations based on laterality for most of the parameters considered. The diameters and circumference in the diaphysis are the only parameters which displayed significant differences, but only in certain groups of fetuses, and therefore the clavicle's growth and development in intrauterine life appears to be a practically symmetrical phenomenon, whereas the bilateral 
variations which are observed in adult clavicles appear to be due to factors which play a role after birth.

According to Trinkaus et al. [16], the asymmetries are more notable in the widths of the diaphysis than in the length, and the widths of the diaphysis are more sensitive to loads than the lengths. Therefore, a closer concordance would be expected in the asymmetries of widths, if the elements are subjected to similar load magnitudes. The clavicle acts as a functional component of the upper limb, in which the differences in activity play an important role [17], having found differences between the various groups studied (farmers, hunter-gatherers and industrial workers). It is also believed that the differences in clavicle length could be due to the fact that clavicle growth is delayed due to repeated axial compression of the upper limb during primary growth.

In his studies, Papaionnoau et al. [8] obtained the best results in terms of accurate classification using the maximum length and circumference at the midpoint of the diaphysis. In his work, he discusses how sexual dimorphism has frequently been attributed to differences in activity patterns, when in actuality the correlation of muscular markers appears to be greater with body size than with sex. It is also believed that the differences may be related to a combination of diet and the sexual division of labor in the recent past.

In his studies on the clavicle, Rios $[4]$ concludes that the result of the morphological differences observed between the sexes is due to genetic and environmental factors which affect growth and development. The length of the clavicle is to be classified as an intermediate-late growth variable, and the minimum diameter of the clavicle as an intermediate-very late variable. There is a significant relationship between the growth pattern and sexual dimorphism in the human skeleton. The parts with earlier growth are generally less sexually dimorphic than the elements that undergo late growth. The increase in robustness in the skeleton, measured by growth in clavicle diameter, continues in adult life and is not constrained by the fusion of the epiphysis. One could say that adult size is first reached, and then the increase in postcranial skeletal robustness occurs, in what is the last stage of human growth. A different pattern of activity between the sexes which involves differential mechanical stress on the shoulder girdle may explain part of the sexual dimorphism found.

In reference to clavicle curvature Kaur et al. [30] has reported that males' bones are more curved than those of females in different populations, and that the length of the left clavicle was greater than that of the right, arguing that with use of the right hand, the right clavicle's curve in adults would become more notable than the left clavicle's, and this would cause the right clavicle to become shorter.

In this study, all of the variables determined, both metric and volumetric, are greater in males and on the right side, with the exception of maximum length and sagittal diameter at the distal end in males. In the last case these differences are not statistically significant. The differences by side found in the metric measurements taken on the distal end are not statistically significant. This contrasts with the distal volume which differences are statistically significant by side. In this last case it is considered the whole region of the distal part which shows differences by side, but with the metric measurements there are considered only specific points of this region which in this sample do not show differences by side. More studies will be needed to know what part or parts of the distal region are contributing to the dimorphic differences by side found in the distal volume.

The diaphysis seems to display greater dimorphism than the proximal and distal regions of the clavicle, among both males and females. Better results are obtained using classification intervals for the diaphysis volume and also for the diameters at midshaft. It is curious that in males there are no statistically significant differences by side in the diaphysis volume but there are in the diameters so further studies will be necessary to study the different parts of the diaphysis because the central region appears to have differences by side. The action by the muscles of the proximal and distal regions, would influence the curved morphology of the bone and would add tension to the medial portion of the bone, fomenting its remodeling by increasing its robustness in response to this stress [35]. This could explain the differences by side found in the diameters because this central region is suffering special stress which would be greater in the predominant limb.

The curve of the human clavicle is typical and differs from that of other primates. In general, comparing the degree of asymmetries between humans and other primates (apes and monkeys), it has been seen that the percentage distribution and relative quantity of asymmetries in the clavicle and in the long bones of the upper end differ especially, but this is not so at the lower end, where the differences found are similar [15]. In the study of curvature indices, it has been found that the anterior and posterior curve does not show statistically significant differences by side but that clavicles which are shorter have the two curves or one of them more pronounced (75\% in males/89\% in females when the right clavicle is shorter and $65 \%$ in males/69\% in females when the left clavicle is shorter). The only statistically significant difference is found in the left anterior curve being this curve greater in males. Entering at the proximal end is the distal portion of the pectoralis major and the costoclavicular ligament, which is a powerful stabilizer, and entering at the distal end are the trapezium and deltoid muscles. Pectoralis major enters the diaphysis in its anterior portion covering $2 / 3$ parts of the anterior curve so this region is specially suffering the action of this muscle and could influence remodeling curve's shape increasing its curvature. In males volume diaphysis results show less bilateral asymmetry than in females so if anterior region do as well, this could explain why only the left side shows statistically significant differences by sex.

Shirley [35] and Fatah et al. [19] found that the differences in terms of length were more notable in males than in females. On the other hand, as for the remaining differences, they were more notable in females, with the exception of the contours of deltoid origin and the entry of the trapezium at the distal end, where the differences are more notable in males. They also found that the most significant differences in both sexes were found at the lateral end on its superior surface, in the diaphysis on its inferior surface, and at the medial end on its anterior surface. Most of these locations are muscular entry sites. The entry sites which are found to be significant areas of asymmetry are the pectoralis major and the anterior portion of the deltoid, as well as the inferior portion of the subclavius. There is also an area on the posterior portion of the diaphysis which displays significant differences, and in males another small region at the medial end. Undoubtedly geometric morphometric studies of this type in the present sample would add more information about which specific regions have more dimorphism by side and sex and compare these differences among populations.

The results found in prior studies and in this study seem to confirm that the left clavicle is longer than the right clavicle, but that the latter is more robust. The clavicle normally acts like a support for attachment and conveys forces axially from the upper limb to the thorax. The reasons why right clavicles are shorter may be related with an increase in the compression forces on the shoulder girdle of the dominant side [17] which could increase the curvature and bring the two ends nearer or produce an earlier bony union of the epiphysis [13]. Also adding to these differences on one side could be the differences in muscular development associated with the predominance of one limb over the other, or the tendency to favor one side over the other when completing daily tasks [40]. The differences in length could also be correlated with the 
asymmetrical development of the areas where the trapezoid and costoclavicular ligaments are joined. The trapezoid ligament plays a predominantly restrictive role in the movement of the acromioclavicular joint during axial compression, with large amounts of force, whereas the costoclavicular ligament limits both the lifting of the pectoral belt and the upward displacement of the medial end of the clavicle. Those clavicles in which these ligaments suffered greater tension also tended to be the shorter side [17].

\section{Conclusions}

Volume turned out to provide the greatest discriminatory power, with right diaphysis volume being the variable which best determines sex using the clavicle, accurately classifying $94 \%$ of all cases, followed by the total volume, which accurately classifies $92 \%$ of all cases.

Of the metric variables, that which best determines sex is right sagittal diameter at midshaft, accurately classifying $90 \%$ of all cases, followed by the right maximum length, which accurately classifies $90 \%$ of all cases

Left clavicles are of greater length than right clavicles, though the latter are more robust. The curvature indices reveal that right clavicles have a more pronounced posterior curve in males and females and a more pronounced anterior curve in females but these differences are no statistically significant. The only statistical significant difference between sexes has been found in the left anterior curve being that of males more curved than females.

Both the final morphology and the differences found between males and females could be due to a convergence of factors of a genetic and environmental nature. The stress and tension which act on the bone lead to changes which affect both the surface and the mineral content. These changes occur gradually throughout growth and life. The bone's response to the stress and tension to which it is subjected will be different depending upon the bone's resistance, which is different for each individual and for each of the sexes.

\section{Acknowledgments}

We would like to thank the Calculation Center of the Universidad Complutense of Madrid for having made the Picza 3D laser scanner and the software to be able to perform the threedimensional scanning available to us.

\section{References}

[1] A.E. Ljunggren, Clavicular function, Acta Orthop. Scand. 50 (1979) 261-268

[2] I. Jit, S. Singh, The sexing of the adult clavicles, Indian J. Med. Res. 54 (6) (1966) 551-571.

[3] J.P. Patel, R.K. Shah, S.P. Merchant, A.B. Nirvan, G.V. Shah, Sexing of the human adult clavicle in Gujarat zone, Gujarat Med. J. 64 (2) (2009) 40-46.

[4] L. Ríos Frutos, Determination of Sex from the Clavicle and Scapula in a Guatemalan Contemporary Rural Indigenous Population, Am. J. Forensic Med. Path. 23 (3) (2002) 284-288.

[5] I.L.O., Sex determination from the bones of the forearm in a modern South African simple, in: Master Thesis, University of Pretoria, 2007.

[6] M.K. Spradley, R.L. Jantz, Sex estimation in forensis anthropology: skull versus postcranial elements, J. Forensic Sci. 56 (2) (2011) 289-296.

[7] M.K. Haque, D.I., Mansur, A., Krishnamurthy, R., Karki, K., Sharma, R. Shakya, Morphometric Analysis of Clavicle in Nepalese Population. Kathmandu Univ. Med. I. 9(3) 35 (2011) 193-197.

[8] V.A. Papaioannou, E.F., Kranioti, P., Joveneaux, D., Nathena, M. Michalodimitrakis, Sexual dimorphism of the scapula and the clavicle in a contemporary Greek population: Applications in forensic identification. Forensic Sci. Int. (2012) 217:231.e1-231.e7.

[9] P.S. Bhusareddi, K.V. Padeyappanavar, Sex determination of adult human clavicles by various anthropometric measurements, Anatomica Karnataka 6 (2) (2012) 56-62.

[10] M. Akhlaghi, B. Moradi, M. Hajibeygi, Sex determination using anthropometric dimensions of the clavicle in Iranian population, J. Forensic Leg. Med. 19 (2012) $381-385$.

[11] M.L. Tise, M.K. Spradley, B.E. Anderson, Postcranial sex estimation of individuals considered hispanic, I. Forensic Sci. 58 (S1) (2013) S9-S14, http://dx.doi.org/ 10.1111/1556-4029.12006.

[12] J. Albanese, A method for estimating sex using the clavicle, humerus, radius and ulna, I. Forensic Sci. 58 (6) (2013) 1413-1419.

[13] F.G. Parsons, On the proportions and characteristics of the modern English clavicle, J. Anat. 51 (1916) 71-93.

[14] D. Singh, I. Jit, Identification of sex from the volumen of the clavicle, I. Anat. Soc. India 45 (2) (1996) 119-124.

[15] A.H. Schultz, Proportions, variability and asymmetries of the long bones of the limbs and the clavicles in man and apes, Hum. Biol. 9 (3) (1937) 281-328.

[16] E. Trinkaus, S.E. Churchill, C.B. Ruff, Postcranial robusticity in Homo. II: Humeral bilateral asymmetry and bone plasticity, Am. J. Phys. Anthropol. 93 (1994) 1-34.

[17] S. Mays, J. Steele, M. Ford, Directional asymmetry in the human clavicle, Int. J. Osteoarchaeol. 9 (1999) 18-28.

[18] B.M. Auerbach, M.H. Raxter, Patterns of clavicular bilateral asymmetry in relation to the humerus: variation among humans, J. Hum. Evol. 54 (2008) 663-674.

[19] E.E.A. Fatah, N.R., Shirley, M.R., Mahfouz, B.M., Auerbach, A. Three-dimensional analysis of bilateral directional asymmetry in the human clavicle. Am. J. Phys. Anthropol. 149 (2012) 547-559.

[20] A. Mohsin, Z., Alam, Ekramuddin, N.A. Faruqi, Bilateral variations in the growth and development of human foetal clavicle. Biomed. Res. 24(2)(2013)235-241.

[21] B.P. Cunningham, A. Mclaren, M. Richardson, R. McLemore, Clavicular length: The assumption of symmetry, Orthopedics 36 (3) (2013) e343-e347.

[22] M. Ledger, N. Leeks, T. Ackland, A. Wang, Short malunions of the clavicle: An anatomic and functional study, J. Shoulder Elbow Surg. 14 (4) (2005) 349-354

[23] R. Lugo, P. Kung B. Ma Shoulder biomechanics, Eur. J Radiol. 68 (2008) 16-24

[24] M. Iannolo, F.W. Werner, L.G. Sutton, S.M. Serell, S.M. VanValkenburg, Forces across the middle of the intact clavicle during shoulder motion, J. Shoulder Elbow Surg. 19 (2010) 1013-1107.

[25] B. Patel, P.A. Gustafson, I. Jastifer, The effect clavicle malunion on shoulder biomechanics; A computational study, Clin. Biomech. 27 (2012) 436-442.

[26] R.J. Hillen, B.J. Burger, R.G. Pöll, C. Niek van Dijk, D. Veeger, The effect of experimental shortening of the clavicle on shoulder kinematics, Clin. Biomech. 27 (2012) 777-781.

[27] A. Bachoura, A.S. Deane, J.N. Wise, S. Kamineni, Clavicle morphometry revisited: a 3-dimensional study with relevance to operative fixation, I. Shoulder Elbow Surg. 22 (2013) e15-e21.

[28] N. Matsumura, N. Nakamichi, H. Ikegami, T. Nagura, N. Imanishi, S. Aiso, Y. Toyama, The function of the clavicle on scapular motion: a cadaveric study, I. Shoulder Elbow Surg. 22 (2013) 333-339.

[29] G. Olivier, Anthropologie de la clavicule. Bull. Mém. Soc. Anthrop. 10 (1951) 6799, 121-157.

[30] H. Kaur, Harjeet, D., Sahni, I., Jit, Length And Curves of The Clavicle In Northwest Indians. J. Anat. Soc. India 51(2)(2002)199-209.

[31] Z.J. Daruwalla, P. Courtis, C. Fitzpatrick, D. Fitzpatrick, H. Mullett, Anatomic variation of the clavicle: a novel three dimensional study, Clin. Anat. 23 (2010) 199-209.

[32] M.K. Haque, D.I. Mansur, K. Sharma, Study on Curvatures of Clavicle with its clinical Importance, Kathmandu Univ. Med. J. 36 (4) (2011) 279-282.

[33] A. Bernat, T., Huysmans, F. Van Glabbeek, J., Sijbers, J., Gielen, A. Van Tongel A, The Anatomy of the Clavicle: A Three-dimensional Cadaveric Study. Clin Anat (2013) DOI: $10.1002 /$ ca.2228810.1002/ca.22288.

[34] N.R. Shirley, Age and Sex Estimation from the Human Clavicle: An Investigation of Traditional and Novel Methods, PhD Thesis, 2009.

[35] E. Ruiz Mediavilla, B. Perea, E. Labajo, J.A. Sánchez, A. Santiago, E. Dorado Determining sex by bone volumen from 3D images: discriminating analysis of the tali and radii in a contemporary Spanish reference collection, Int. J. Legal Med. 126 (2012) 623-631.

[36] B. Calais-Germain, Anatomía para el movimiento. Ed. Los libros de la liebre de marzo, 1995.

[37] K.E. Stull, M.L. Tise, Z. Ali, D.R. Fowler, Accuracy and reliability of measurements obtained from computed tomography 3D volume rendered images, Forensic Sci. Int. 238 (2014) 133-140.

[38] T. Adao Perini, G. Lameira de Oliveira, J. Dos Santos Ornellas, F. Palha de Oliveira, Technical error of measurement in anthropometry. Rev. Bras. Med. Esporte vol. 11 (1) $\mathrm{Jan} / \mathrm{Feb}$ (2005) 86-90.

[39] C.Y. Fung, Biomechanics Mechanical properties of living tissues. Ed. Springer, 1997.

[40] C.N. Shaw, Is hand preference coded in the hominin skeleton? An in-vivo study of bilateralmorphological variation. J. Hum. Evol. 61 (2011) 480-487. 